\title{
PENGEMBANGAN LEMBAR KERJA PESERTA DIDIK (LKPD) BERBASIS CREATIVE PROBLEM SOLVING (CPS) PADA PEMBELAJARAN TEMATIK TERPADU DIKELAS IV SD
}

\author{
Hazari Nur Faizah ${ }^{1}$, Reinita ${ }^{2}$ \\ 1,2Pendidikan Guru Sekolah Dasar, Universitas Negeri Padang, Indonesia \\ 1nurfaizahhazari@gmail.com,2reinita1652@fip.unp.ac.id
}

\begin{abstract}
The purpose of this study was to develop valid and practical Student Worksheet (LKPD) based on Creative Problem Solving (CPS) in Integrated Thematic Learning in Fourth Grade Elementary School using the $4 D$ development model. The stages of the 4D model are Define, Design, Develop and Disseminate. The subjects of this study were 3 experts, 2 fourth grade teachers and 32 fourth grade students at SDN 16 Payakumbuh and SDN 32 Payakumbuh. The instruments used in this study included expert validation sheets and teacher and student response questionnaires. The results of this study show: 1) Student Worksheets (LKPD) Based on Creative Problem Solving (CPS) in integrated thematic learning in grade IV SD, it is declared valid to be used by material, language and media experts to get an assessment with an overall average of $91.03 \%$ validators (2) the teacher's response to the LKPD based on Creative Problem Solving (CPS) in the integrated thematic learning in grade IV SD, it is a very practical category that gets an assessment with an average value of $89.58 \%$ (3) the student's response to the LKPD based on Creative Problem Solving (CPS) in the integrated thematic learning in grade IV SD, the high category gets an assessment with an average of $89.46 \%$
\end{abstract}

Keywords: Student Worksheet, Creative Problem Solving 4DModel

\begin{abstract}
ABSTRAK
Tujuan dlakukna nya pngembngan ini adaalah guna mengembangkan Lembar Lembar Kerja Peserta (LKPD) Beerbasis Creative Problem Solving (CPS) dii pembellajaran Teematik Terrpadu Dikels IV SD yang valid dan praktis yang mengunakan model pengembangan 4D . langkah 4D adalah Deffine, Dessign, Devvelop dan Diisseminate. Subjek penelitian ini yaitu 3 orang ahli, 2 orang guru kelas IV dan 32 orang peserta didik kelas IV di SDN 16 Payakumbuh dan SDN 32 Payakumbuh. Intrumen yagn dipakai pada penelitian ini antara lain lembar validasi ahli dan angket respon guru dan peserta didik. Hasilny menunjukan : 1) Lemmbar Keerja Peserta Didik (LKPD) Berbasis Creative Problem Solving (CPS) Pada pembelajaran Tematik Terpadu Dikelas IV SD dinyatakan valid digunakan oleh ahli materi, bahasa dan media mendapatkan penilaian dengan rata-rata
\end{abstract}


sseluruhan validator $91,03 \%$ (2) respon guru terhadap LKPD berbasis Creative Problem Solving (CPS) Pada pembelajaran Tematik Terpadu Dikelas IV SD memperoleh kategori sangat praktis yang mendapatkan penilaian dengan nilai rata-rata $89,58 \%$ (3) respon peserta didik terhadap LKPD berbasis Creative Problem Solving (CPS) Pada pemmbelajaran Tematik Terpadu Dikelas IV SD memperoleh kategori tinggi yang mendapatkan penilaian dengan rata-rata $89.46 \%$

Kata kunci : LKPD, Creative Problem Solving, Model 4D

\section{A. Pendahuluan}

Pendidikan merupakan dilakukan sadar dan terencana agar mewujutkaan pembelajaran supaya murid dengan aktif dapaatt menyalurkan potensi diri nya untuk mempunyaii kekuataan spiritual keagamaan, pengendalian diri, serta keterampilaan yang dibutuhkan diirinya, masyarakat, bangsa, dan negara.

Menurut (Astuti, Danial, and Anwar 2018) Kurtilas mendambakan pembelajaran yang lebiih berpusat dan aktif pada peserta didik untuk menyalurkan kreativitas serta menciptakan kondisi yang menciptakan susana menyenangkann,menantaang dan kontekstual".

Menurut (Efendi and Reinita 2019) "Penerapan belajaar dengan menggunakann kurikulum 2013 dilakukan dengan menggunakan pendeekatan pembelajjaran tematiiik, pembelajaran beroriientasi pada teeema dii pembelaajaran. Setiaap teema merupakan campuran darii mapel yang terkoneeksi antarr satu dengan yang lainnya"

Menurut Majid (dalam Efendi and Reinita 2019). "permulaannyaa pembelajaran terpadu diikembbangkan agar dapat membangun ppembelajaran dii dalaamnya siiswa sendiiri aktip dengan mental membanguun pengetahuannya dengan patokann struktur kognitif yang telah ada pada dirinya".

Dapat ditarik kesimmpulan bahhwa pembelajaran tematiik merupakan pembelajaran yanng beeberapa mapel digabungkan ke dalam teeema. (Efendi and Reinita 2019) Menjelaskan" proses belajar bergantung terhadap aktivitas belajar dan dapat membangkitkan semangat dalam dirii peserta didiik untuk belajar dan membangun pengetaahuan yaang dimiliiki siswa"

Kualitas pendidikan nasional 
masih memprihatinkan dan perlu peningkatan sisteem pendidiikan naasional saangat dibutuhkan supaya mutu pendidikan meningkat upaya menningkatkan kuualitas pendidikn dengan cara memperbaiiki profesionalitas guru. (Widayati 2014:87).

Wawancara yang telah peelitii lakuukan IV SDN 16 Kecamatan Payakumbuh Timur Kota Payakumbuh haari Selaasa dan Raabu tanggaal 1516 Desember 2020, dijelaskan bahwa pembelajaran di SDN 16 Payakumbuh belum berjalan maksimal seperti yang diharapkan. Guru kelas IV di SDN 16 Payakumbuh melaksanakan proses belajar mengajar berpedoman pada Buku Guru, Buku Siswa ditambah dengan LKS sebagai penunjang. LKS juga belum digunakan secara maksmial. LKS merupakan Lembar Kerja Siswa yang digunakan dan diikembangkan pada kurikulum 2006 sedangkan SDN 16 Payakumbuh sudah menggunakan Kurikulum 2013 Dan masih belum melakukan pembaharuan sesuai kurikulum yang digunakan saat ini yang harusnya memperbaharui LKS dengan LKPD (Lembar Kerja Peserta Didik).

Seperti yang diketahui saat sekarang ini Sekolah sudah menerapkan Kurikulum 2013 dan di SDN 16 Payakumbuh juga sudah menggunakan Kurikulum 2013. Ketikaa proses pembelajaaran tenaga pendidik memakai soal yang ada di dalam buku siswa dan ditambah dengan buku penunjang yaitu LKS. Peserta didik juga kurang aktif dan bersemangat dalam pembelajaran. Guru kelas juga belum memiliki bahan penunjang sendiri untuk membantu proses pembelajaran. Ini juga membuat peserta didik kurang bersemangat di dalam belajar. Apalagi ditengah maraknya Pandemi Covid-19 saat ini peserta didik tidak diperbolehan kesekolah untuk mengantarkan tugas.

Hanya orang tua yang diminta mengantar tugas peserta didik setiap minggunnya. Tugas dikirim guru kelas dalam Grup belajar di Aplikasi WhatsApp jadi bagi orang tua yang menginginkan anaknya tetap belajar masih berusaha maksimal untuk membimbing anaknya dirumah sedangkan peserta didik yang kurang mendapat perhatian dari orang tua mengakibatkan tugas yang diberikan guru menjadi menumpuk dan tidak terselesaikan. Hal ini mengakibatkan peserta didik yang mendapatkan 
perhatian dirumah akan selalu mendapatkan nilai bagus padahal tingkat kemampuannya rendah dan murid dengan kemampuan tinggi terkadang belajarnya menjadi terhalang karna tidak adanya Handphone, tidak diberikan bimbingan oleh orang tua ataupun dengan kurangnya pemahaman orang tua dengan keadaan saat ini. Proses pembelajaran disekolah dilakukan secara berlanjut setiap harinya kecuali hari libur, bagi peserta didik yang kurang memahami materi ini akan menjadi hambatan mereka dalam mengerjakan soal dan membuat tugas yang diberikan guru.

Solusi dari masalah yang dihadapi saat ini perlunya dikembangkan suatu Lembar Kerja sebagai tambahan penunjang paada proses belajar untuk pellaksanaan pembelajaran. Dapaat disimpulkaan proses pembelajaran adaalah proses komunikasi. Solusi mengatasi masalah ini yaitu mengembngkan inovasi dengan Leembar Kerja Peserta Didik yang bisa meningkatkan keterampilan berffikir siiswaa. Pengembangan Lembar Kerja Peserta Didik memiliki karakteristik dan kebutuhan peserta didik berupa Lembar Kerja Peserta
Didik (LKPD) dengan memakai Model Creative Problem Solving(CPS).

Alasan mengapa LKPD dijadikan solusi untuk memudahkan masalah yg terjadi di SDN 16 Payakumbuh karna LKPD yang dikembangkan memuat pertanyaaan yang dapat diiiselesaikn siswa secara mandiri yagn diingnkan dapat mempermudahh muritt dalam memahami pembelajaran. Prastowo (dalam Amelia, Anshory, and Yunus Saputra 2020) menyebutkan fungsi LKPD yaaitu " Penuntun ketika beelajar, penguatann,aalat bantuw mengembanngkan konnsep dan menemmukan sertaa mengemmbangkan keteraammpilan prroses".

Modell yanng dapat dipaakay untk mengeembangknan Lembaar Kerjaa Peseerta Diidik yaitu Model Creaative Problem Solving (CPS). (Zahara, 2012) "Moddel pembelajaran Creative Problem Solving (CPS) adalah moodel yang berpusat pada pengajaaran dan keteraampilan pemeecahan masaalah, dengan penguaatan keteerampilan". Dengan menggunaakan modeel inii diinginkan dapaat meniinggkattkann minat, kreatif dan metode siswa dalam pembelajaran sehingga siswa mendapatkan manfaat yang maxsimal 
dari segi proses manapun hasil belaajar langkah - langkah pembelajaran dari model Creative Problem Solving (CPS) menurut (Shoimin, 2014:57) "Diawali dengan (1) klarifikasi masalah oleh guru,(2) mengungkapkan pendapat,

evaluasi dan pemilihan dan tahap terakhir yaitu(4) implementasi penyelesaiaan masalah yang diperoleh peserta didik"

Fungsi LKPD menurut (Prastowo A, 2012, hal.270) adalah sebagai berikut: Sebagai penunjang pembelajaran yaangg dapatt menguraagin perrran penddiddikan, tetaapii mengaktifkan siiswa. 2) supaya lembar kerja dapatt memudahkaan murrit untuk memahami materi yang diberikan. 3) agar lembar kerja yang simple dan bayak tugass unntukk berlatiihh.

4)

Menggampanggkan peelaksanaann pembelajarann kepaaada murid.

LKPD menggunakaan model Creative Problem Solving (CPS) dikembanggkan dengan menarik sehingga bisa meningkatkann motivvasii ssiswa daalam mengikuuti pemmbellajaraan. Selain dapat memotivasi peserta didik dalam belajar, pengembangan LKPD berbasiiis Creative Problem Solving (CPS) juga bisa meniningggktkn keterampilan berffikir kreatif serta meningkatkan aspek pemecah massalah yaangg dibeerikaan olleh tennagaa penddiddik. LKPD dikembaaangkaan di pemmbelaajarann temmatik teerpadu.

Pembellajaran tematik terpadu aadallah pembelajaran yang memakai temaa ketika pembelajarann, dimana setiap tema memiliki materi pembelajaran yang dapat dihubungkan maple satu dengan maple lainn dalam pembelajaran. Menurut Sukerti, Marhaeni dan Suarni (dalam Audina and Reinita 2019) "Pemmbelajaaran tematik merupakann pembelajarran deeengan memaadukan brerbagai maata pelajaaran daalam saatu temaa/topiik".

Berdasarkan pendapat tersebut disimpulkan pembelajaran temattikk adalahn pembelaajaran yaang meengaittkan bebeerapaa mataa pelaajaran daalam saatu temaa terrtentu sehhingaga pembelaajaraan ini dapat lebih efektif dan efisien.

Berdasarkan latar belakang masssalah yaang suudahh dijellaskan, rumusaan maasalah daalam peenelitian inii merupakanh 1Bagaimanakah Pengembaangan Lembar Kerja Peserta Didik (LKPD) 
Berbasis Creative Problem Solving (CPS) Paada Pembeelajaraan

Temaatik Terpadu di Kelas IV SDN 16 Payakumbuh yang valid?

2.Bagaimanakah Penggembangan

Leembar Kerrja Peseerta Didik (LKPD)

Berbasis Creative Problem Solving (CPS) Pada Pembelajaran Tematik Terpadu di Kelas IV SDN 16 Payakumbuh yang Praktiis?

Tujuan penelitian pengembangaaan inii yaaiituu :

1.Mengembangkn Lembar Kerja Peserta Didik (LKPD) Berbasis Creative Problem Solving ( CPS) Pada Pembelajaran Tematik Terpadu di Kelas IV SDN 16 Payakumbuh yang valid.

2. Mengembanggkan Lembar Kerja Peserta Didik (LKPD) Berbasis Creative Problem Solving ( CPS) Pada Pembelajaran Tematik Terpadu di Kelas IV SDN 16 Payakumbuh yang praktis.

\section{B. Metode Penelitian}

Penelitiiian yang dilakukn adalah peneliitian pengembangaaan. Model yang diigunakan adalah moodel pengembangan 4-D menurut Thiagarajan (dalam Trianto, 2012:93) yang mana tahap pengembangannya

meliputi tahap I yaitu Deffine, tahap II yaitu Dessign, tahap III Devvelop, dan tahap IV yaitu Disseeeminate. Pada tahap Disseminate tidak peneliti lakukan, dikarenakan tidak semua sekolah saat ini melakukan pembelajaran tatap muka karena masih banyaknya guru yang Re-aktif dan sekolah yang terkena dampak Covid-19 jadi jika tahap penyebaran atau disseminate peneliti lakukan maka akan terkendala biaaya yang besar dan waktu penyebaran yang cukup lama. Maka sebab itulah peneliti hanya melakukan sampai tahap pengembangan (develop). Penelitian ini dilakukan mulai tanggal 5 Mei-6 Mei 2021.untuk sekolah uji coba dan 7 mei8 mei 2021 untuk sekolah penelitian. Subjek penelitian adalah 3 orang ahli dari ahhli mateeri,ahli bahhasa dan aahli meddia, 1 orang guru kelas IV di SDN 32 payakumbuh, 1 orang tenaga pendidik dikelas IV di SDN 16 payakumbuh, 15 orang siswa kelas IV di SDN 32 payakumbuh dan 17 orang siswa di SD N 16 Payakumbuh. Desain penelitian yang digunakan adalah desain penelitian pengembangan model tahap I yaitu Define, tahap II yaitu Design, tahap III Develop, 
Tahap pendefenisian (Define) data praktikalitas yang diambil dari hasil untuk mendeefenisikan syaratt pengisian angket atau respon guru dan pembelajaran dimulai dengan analisis siswa terhadap Lembar Kerja Peserta tuujuan Lembar Kerja Peserta Didik Didik berbasis Creative Problem yang dikembangkan

Tahaap Perancangan (design). Tujuan tahap ini adalah menyiapkan Solving(CPS) yang akan dikembangkan.

Metode pengumpulan informasi Lembar Kerja Peserta Didik yang akan dikembangkan. Kegiatan yang dilakukan addalah merancang Lembar Kerja Peserta Didik Lembar Kerja Peserta Didik dirancang untuk kelas IV SD, pada Tema 8 "Daerah Tempat Tinggalku" subtema 1 Lingkungan Temppat Tiinggalku Pembelajaran 3 dan pembbelajaran 4 ini akan dirangkum dalam satu Lembar Kerja Peserta Didik.

Tahap . Pengeemmbangan (develop). tahap inni mengghasilkaan Lembar Kerja Peserta Didik yaang sudah direeviisi berdasarkaaan masukan dari para ahlii. Jenis daaata yang diaambil daalam penelilitian ini yaituu data yang diambil secara langgsung oleh penulis dari lapangan. Data yang pertama adallah dari hasil angket Lembar Kerja Peserta Didik berbasis Creative Problem Solving(CPS) yang akan diisi validator. Validator ini dipilih dari dosen yang ahli dibidangnya. Data yang kedua yaitu berperan buat memperoleh data- data yang hendak dianalisa. Metode pengumpulan informasi dalam riset ini ialah memakai lembar validasi dan Angket praktikalitas( angket guru serta peserta didik) Lembar validasi yang digunakan meliputi lembar validasi buat pakar konten serta pakar bahasa serta pakar media. Angket praktikalisi yang digunakan meliputi angket buat guru serta murit. Skala yag digunakan skala kevalidan.

Informasi yang diambil dari riset ini merupakan informasi yang diambil dari hasil validasi LKPD oleh para pakar. Serta informasi yang diambil dari penerapan uji coba berbentuk informasi kepraktisan LKPD berbasis CPS. Berikut skor validitas kelayakan LKPD:

\section{Tabel 1. Skor validitas LKPD berbasis CPS}

\begin{tabular}{|c|c|}
\hline Skor & Kategori Kelayakan \\
\hline 1 & Kurang Baik \\
1 & \\
\hline 2 & Cukup Baik \\
\hline
\end{tabular}




\begin{tabular}{|c|c|}
\hline & Baik \\
\hline 3 & Sangat Baik \\
\hline 4 & Modifikasi Riduwan
\end{tabular}

(2019:89)

Tabel 2. Kategori Kelayakan LKPD berbasis CPS

\begin{tabular}{|l|c|}
\hline Rentang $\%$ & Kategori \\
\hline $81,26-100,00$ & Valiid \\
\hline $62,51-81,25$ & Cukup Valiid \\
\hline $43,76-62,50$ & Kurang Valiid \\
\hline $25,00-43,75$ & Tidak Valiid \\
\hline
\end{tabular}

Sumber:Modifiikasi dari Fauuda

(2015:859)

Untuk menggukuur hittungan akhir hasil memakai rumus Riduwan dan Sunarto (2015:38), yaitu:

$\bar{X}=\frac{\sum x i}{n} \times 100 \%$

Keterangan :

$\bar{x}=$ Rerata

$\sum x i=$ Jumalah nilai dari setiap validator $\mathrm{n}=$ Jumlah validator

Anaallisaa Daata Praktisi LKPD, teknis aanallisiss praktikalitas digunakan untuk analisis hasil pengamatanketerlaksanaannya angket respon tenagaa penndidiik danmuuriit terhadaap prosess suaatu pemmbelajaran yanang dianalissis denggan meenggunakan keetentuan sepperti tabbel berikut ini :

Tabel 3. Skala Respon Guru dan
Peserta Didik.

\begin{tabular}{|c|c|}
\hline Rentang & Konversi \\
\hline 1 & $\begin{array}{c}\text { Sangat Tidak } \\
\text { Settuju }\end{array}$ \\
\hline 2 & Tidak Setujuu \\
\hline 3 & Setuiju \\
\hline 4 & Sangat Setuju \\
\hline
\end{tabular}

Modifikasi Dimyati

(2013:161)

mengukurr tingkat kepraktis dilaksnakan dengan rumuus menurut Rahmaat dan Irrfan (2019:50) sebagai berikut:

Nilai Kepraktiisan (\%) :

$\frac{\text { skor yang diperoleh }}{\text { skor maksimal }} \times 100 \%$

Tabel 3. Skala Nilaii Kepraktisan

\begin{tabular}{|c|c|c|}
\hline No & $\begin{array}{c}\text { Skor dalam } \\
\text { persen }\end{array}$ & Kategori \\
\hline 1. & $0 \%-25$ & Tiidaik praktiis \\
\hline 2. & $>25-50$ & Kurang praktiis \\
\hline 3. & $>50 \%-75$ & Praktiis \\
\hline 4. & $>75 \%-100$ & Sangat Praktiis \\
\hline
\end{tabular}

(2019:51)

Sumber : Rahmat dan Irfan

HASIL DAN PEMBAHASAN

\section{Analisis Hasil Uji Validitas LKPD berbasis CPS}

\section{Hasil Uji Validitas Ahli Materi}

Uji coba ahli materi dilakukan oleh Atri Waldi, S.Pd,M.Pd, yang merupakan dosen PPKn PGSD FIP UNP. Pengambilan data uji coba dilakukan 
tanggal 19 Maret 2021. Hasil memberikan interaksi (pemberian perhitungan uji coba berdasarkan respon), komunikasi visual, dan urutan aspek kelayakan isi yang berisikan sajian sistematis. Sedangkan pada kesesuaian KI, Indikator pembelajaran, indikator kegrafikan berisikan desain tujuan pembelajaran dan Kebenaran tampillan menarik, tata lettak baik, dan substansi materi pembelajaran tentang pembelajaran tematik terpadu tema 8 Subtema 1 pembelajaran 3\&4. Hasil analisis data data akhir dari ujicoba ahli materi ini 93\%

\section{Hasil Uji Validitas Ahli Bahasa}

Uji coba ahli kebahasaan dilakukan oleh Ari Suriani, S.Pd, M.Pd selaku dosen bahasa PGSD FIP UNP. Pengambilan data dilakukan tanggal 24 Maret 2021 yang hasil perhitungannya berdasarkan indikator Kebahasaan. Indikator kebahasaan berisikan tentang keterbacaan teks dan penggunaan bahasa secara efektiif dan efisiien (jelas dan singkat). Adapun hasil analisis dari ahli bahasa adalah $87,5 \%$

\section{Hasil Uji Validitas Ahli Media}

Ujii coba ahli Desain media dilakukan oleh Drs. Yunisrul, M.Pd selaku dosen seni PGSD FIP UNP. Pengambilan data dilakukan tanggal 19 Maret 2021 yang hasil perhitungannya berdasarkan indikator penyajian dan kegrafikan. Indikator penyajian berisikan tentang media pembelajaran dapat memberikan motivasi dan daya Tarik, media gambbar dan fototo jelas. Adapun hasil analisis dari ahli media adalah $92,59 \%$.

\section{Analisis Validasi Keseluruhan} Hasil validasi LKPD berbasis CPS secara keseluruhan dari ketiga validator dianalisis dengan menjumlahkan ketiga nilai rata-rata setiap validator dibagi dengan banyak validator

\begin{tabular}{|l|l|l|l|}
\hline No & $\begin{array}{l}\text { Aspek } \\
\text { yang di } \\
\text { validasi }\end{array}$ & $\%$ & Keterangan \\
\hline 1 & $\begin{array}{l}\text { Aspek } \\
\text { Materi }\end{array}$ & $\begin{array}{l}\text { A3\% \% } \\
\text { Bahasa }\end{array}$ & Valid \\
\hline 3 & $\begin{array}{l}\text { Aspek } \\
\text { Media }\end{array}$ & $92,59 \%$ & Valid \\
\hline \multicolumn{2}{|l|}{ Rata- rata } & $\mathbf{9 1 , 0 3 \%}$ & Valid \\
\hline
\end{tabular}

Berdasarkan hasil validasi dari ketiga validator, didapatkan hasil secara keseluruhan validasi LKPD berbasis CPS berada pada kategori "valid". Jadi dapat disimpulkan bahwa LKPD berbasis CPS dinyatakan valid dan dapat digunakan ke lapangan.

Analisis Hasil Uji Praktikalitas LKPD berbsis CPS 


\section{Hasil Uji Praktikalitas (Guru)}

\section{a. Sekolah melakukan Uji Coba Produk}

Pengambilan respon tengaa pendiidik prakttikaliitaas LKPD dilakukan oleh ibu Widra Hayani, S.Pd selaku guru kelas IV SD Negeri 32 Payakumbuh Pengambilan data uji praktikalitas ini dilakukan pada tanggal 5 mei- 6 mei 2021.

Berdasarkan perhitungan lembar praktikalitas didapatkan nilai persentase kepraktisan dari respon guru adalah $87,50 \%$ yang termasuk dalam kategori sangat praktis dengan rentang 3 s/d dapat diterik hasil bahwasannyaa guru menilai LKPD yanng dikembanggkann peneliti sannggat praktis dan daapat membaantu gurru daaalam proses pembelajaran

\section{b.Sekolah melakukan Penelitian}

Pengambilan

respon

guru

terhadap praktikalitas LKPD dilakukan oleh ibu Mayang Puspita, S.Pd selaku guru kelas IV SD Negeri 16 Payakumbuh Pengambilan data uji praktikalitas ini dilakukan pada tanggal 7 mei-8 mei 2021.

Berdasarkan perhitungan lembar praktikalitas didapatkan nilai persentase kepraktisan dari respon guru adalah $91,66 \%$ yang termasuk dalam kategori sangat praktis dengan rentang $3 \mathrm{~s} / \mathrm{d}$. jadi ditarik hasil baahwaa guru menilai LKPD yang dikembangkan peneliti sangat prraktiss daan daapaatt membanntu geruru dallam prowoses pembelajaraan.

\section{Hasil Uji Praktikalitas (Respon Peserta Didik)}

Hasil Uji Praktikalitas Peserta Didik

a. Seko

Pengambilan angkit muuritt terhaadapp prakttikaliatas LKPD dilaakukan oleeh peeserta diiidik kelas IV di SDN 32 Payakumbuh yang berjumlah 15 orang. Pengambilan data uji praktikalitas oleh peserta didik dilaksanakan pada tanggal 5 Mei- 6 mei 2021.

Berdasarkan perhitungan lembar praktikalitas bahwaasannyaa pernyaataan yaang menggambaarkaan kepraaktisaan menunjukkaan nilaai kepraaktisan aadalaah $92,28 \%$ yaang termaasuk kateegori saangat praaktis. Berdaasarkaan penjelaasan terssebut daapatt disimpullkan baahwa secaara umaum peeserta didikkk merasan seenangg dann berseemangaat menggunaakan LKPD berbaasis CPS. Seelain ituu, peesertaa diidik jugaa 
meraasa mempeeroleh penagalaman baaru terhaadap taampilan LKPD yaang telaah dikembaangkaan.

\section{a. Sekolah melakukan Penelitian}

Pengambilan reeespon peseertaa diidik terhadap praaktikaalitaas LKPD dilakukan oollehh peseerta dideik kelas IV di SDN 16 Payakumbuh yang berjumlah 17 orang. Pengambilan data uji praktikalitas oleh peserta didik dilaksanakan pada tanggal 7 Mei- 8 mei 2021.

Bersumber pada perhitungan lembar praktikalitas kalau tiap statment yang menggambarkan kepraktisan menampilkan nilai kepraktisan merupakan $95, \mathbf{2 \%}$ yang tercantum jenis sangat prakktiss. Bersumber pada uraian tersebut bisa disimpulkan kalau secara universal partisipan didik merasan bahagia serta bergairah memakai LKPD berbasis CPS.

\section{Kesimpulan}

1. Bagi peneliti, pengeembangan Leembar Keerja Peserta Didik (LKPD) Berbasis Creativve Probllem Solviing (CPS) pada pembelajaran tematik terpadu di kelas IV SD dapat dijadiikan laandasan untuk melaksanakan penelitian

selanjutnya.
2. Bagi guru kelas IV SD, berdasarkan hasiil praktikalitas Lermbar Kerrja Peserta Didiik (LKPD) Berbasis Creatiive Problem Solviing (CPS) pada pembelajaran tematiik terpadu di kelas IV SD yang dikembangkan dapat digunakan sebagai salah satu alternative cara belajar untuk membantu siswa memahami materi keelas IV temaa 8 (Daerah Tempat Tinggalku) Subteema 1 (Liingkungan Tempat Tinggalku) Pembelajaran 3 dan 4.

3. Bagi sekolah, diharapkan dengan adanya Lembar Kerja Peserta Diidik (LKPD) Berbasiis Creative Problem Solviing (CPS) pada pembelajaran tematik terpadu di kelas IV SD ini diharapkan dapat meningkatkan kualitas pembelajaran siswa.

4. Bagi pembaca, diharapkan mampu menambah pengetahuan serta wawasan mengenai pengembangan Lembr Kerjja Peserta Didiik (LKPD) Berbasiis Creatiive Probleme Solviing (CPS) pada pembelajaran tematik di Kelas IV SD.

\section{DAFTAR PUSTAKA}

Amelia, Delora Jantung, Ichsan Anshory, and Setiya Yunus Saputra. 2020b. "Pengembangan LKPD 
berorientasi metakognisi di sd Workshop Instrumentasi Indsutri. muhammadiyah 5 bumiaji." JINoP Prosiding

(Jurnal Inovasi Pembelajaran).

Astuti, Sry, Muhammad Danial, and

Muhammad

Anwar.

2018

"pengembangan LKPD berbasis PBL (problem based learning) untuk meningkatkan keterampilan berpikir kritis peserta didik pada materi kesetimbangan kimia." Chemistry Education Review (CER).

Audina, Witia and Reinita Reinita. 2019. “penggunaan model Value Clarification Technique (VCT) percontohan untuk meningkatkan proses pembelajaran tematik terpadu di kelas iv sekolah dasar." Jurnal Bahana Manajemen Pendidikan 8(2):61.

Budiyanto, A. K. (2016). Sintaks 45 Metode Pembelajaran Dalam Student Centered =Learning (SCL). Malang:

Universitas Muhammadiyah Malang.

Efendi, Satria and Reinita Reinita.

2019. "Peningkatan Aktivitas Belajar

Siswa Pada Pembelajaran Tematik

Menggunakan Pendekatan Vct Model Matriks Di Sdn 36 Cengkeh Kota Padang." Jurnal Bahana Manajemen Pendidikan 8(2):70.

Fauda, Syifaul. (2015). Pungujian Validasi Alat Peraga Pembangkit Sinyal (Oscillator) untuk pembelajaran

Majid,Abdul.2014. Pembelajaran

Tematik Terpadu. Bandung : PT Remaja Rosda Karya

Prastowo, A. (2012). Panduan Kreatif Membuat Bahan Ajar Inovatif. Jogjakarta: DIVA Press.

Rahmat \& Irfan, Dedy. (2019). Rancang Bangun Media Pembelajaran Interaktif Komputer dan Jaringan Dasar di SMK. Jurnal Vokasional Teknik Elektronika dan Informatika. Vol 7 (1), E-ISSN: 23023295

Shoimin, A. (2014). 68 Model Pembelajaran Inovatif dalam Kurikulum 2013. Yogyakarta: AR-RUZZ MEDIA.

Riduwan,Sunarto (2015). Belajar Mudah Penelitian Untuk GuruKaryawan dan Peneliti Pemula. Bandung: Alfabeta.

Trianto. 2011. Mendesain Model Pembelajaran Inovatif- Progresif. Jakarta : Kencana Prenada Media Group

Widayati, Ani. 2014. "PENELITIAN TINDAKAN KELAS." Jurnal Pendidikan

Akuntansi Indonesia. 